\title{
IMPACT OF ENVIRONMENTAL MEASURES ON ECONOMIC EFFICIENCY OF INDUSTRIAL ENTERPRISES
}

\author{
FRIDHI Bechir*1 \\ ${ }^{1}$ College of Business Administration, Majmaah UNIVERSITY, SAUDI ARABIA. \\ bm.fridhi@mu.edu.sa
}

\begin{abstract}
This article focuses on the reduction of environmental effects which can represent considerable investments for industrial enterprises. These enterprises are faced, on the one hand, with regulatory or societal pressures requiring the adoption of effective depollution systems and, on the other hand, with economic and competitive constraints, which limit unproductive investments, they often have a margin very narrow maneuvering.

We have found that the economic implications of environmental measures seem even more difficult to grasp than studies on the issue yield contradictory results.

Our objective in this article is to recall the main debates on this theme by emphasizing the ambiguous and circumstantial nature of the relationship between environment and economy. The results concluded show that the complexity of this relationship tends to call into question the oftensimplistic opposition between the "win-win" and "win-lose" hypotheses, which dominate the debates on the impact of environmental actions on efficiency economic of industrial enterprises.
\end{abstract}

\section{Keywords}

Economic Efficiency, Environmental Actions, Industrial Enterprises

\section{JEL Classification}

$\mathrm{A} 22, \mathrm{O} 31, \mathrm{M} 12$

DOI: https://doi.org/10.14311/bit.2020.02.04

Editorial information: journal Business \& IT, ISSN 2570-7434, CreativeCommons license (c) (1) published by CTU in Prague, 2020, http://bit.fsv.cvut.cz/

\section{Introduction}

Today, environmental actions represent a strategic challenge for companies. The environment appears today as a collective concern which must be integrated into productive activities. Regulatory and societal pressures for the respect of ecosystems impose constraints, which enterprises cannot avoid without compromising the legitimacy of their activities.

Therefore, opening up to environmental values and investing in pollution control equipment appear to be a necessity to ensure the sustainability of industrial activities. The firm's response to external pressures and social protests is a classic theme for thinking about strategy and economic analysis. Many models, often used in the study of environmental policies, have thus attempted to analyze the 
more or less "proactive" reaction of the enterprise to societal pressures (Schuman, 1995; Freeman, 1984; Pasquero, 1980; Ackerman \& Bauer, 1976; Jolly, 1990).

However, in recent years, these questions have tended to appear more as a source of economic opportunity than as a constraint to which enterprises must submit (Elkington, 1987; Comolet, 1991; Winter, 1989; Dilorenzo, 1991; Shrivastava, 1995; Lanoie and Tanguay, 1999).

\section{Literature review}

The concept of sustainable development, omnipresent in the discourse of enterprises and governments since the end of the 1980s has largely contributed to popularize this "win-win" vision of the relationships between environmental actions and economic interests. In particular, according to "Michael Porter", environmental pressures and green investments help to improve the competitiveness of enterprises as well as that of the countries with the most stringent regulations (Porter, 1991; Porter and Van Der Linde, 1995). Indeed, the reduction of pollution tends to stimulate innovation, to reduce the quantities of materials and energies used, and therefore to increase productivity, which is defined as the "ratio of the product to the factors of production (quantity of energy, working time, etc.), (D. Robert)'. This virtuous logic, which intends to minimize the resources used and the contaminants discharged to improve the efficiency of the processes, is at the center of the quest for eco-efficiency, which has been growing in interest since the late 1990s (De Simone and Popoff, 1997 ; Boiral, and Croteau, 2001).

However, empirical studies of the environment and productivity yield often contradictory results. Some works lend credence to the "Porter hypothesis", while others confirm the classic economic model, which considers pollution as a negative externality, which when taken into account entails costs that can jeopardize enterprises productivity. Debates on this topic have not only strategic implications on the choice of environmental investments but also political and ecological consequences, the economic argument is often put forward to delay or to question the opportunity of some pollution reduction programs.

The objective of this article is not to take a position for one or the other of these apparently contradictory hypotheses but to show their reducing and simplifying character from a more contingent approach of the links between economy and environment. The analysis of these links does not presuppose that the environmental stakes of companies must be judged solely in terms of a "cost-benefit" type of vision, but intends to shed critical light on the economic debates on the question.

First, the main arguments of the classical model and Porter's hypothesis will be exposed. Secondly, the arbitrary and contingent nature of the traditional "cost-benefit" analysis will be underlined. In conclusion, a model allowing to schematize these main determinants and to facilitate the understanding of the economic stakes of environmental actions will be proposed. 


\section{The classical model or the environment as an economic and societal constraint}

According to the classic approach to the relationships between economic and environmental issues, ecological pressures appear as constraints and costs likely to threaten the sustainability of organizations. This approach is essentially based on two complementary analyzes of environmental actions. The first is part of a societal perspective in which the enterprise is subject to external pressures to which it must imperatively respond. The differences between society's expectations and the perception of corporate behavior, often associated with "polluters", therefore pose threats to the legitimacy and survival of organizations (Suchman, 1995). Environmental measures are therefore the source of social pressures that enterprises must be able to analyze and anticipate.

The reinforcement of these pressures is not only likely to compromise the image of the enterprise but also to considerably reduce its room for maneuver due to regulatory constraints, public protests, media campaigns or boycott operations organized by environmental groups (Ackerman and Bauer, 1976; Pasquero, 1979; Boiral and Joly, 1992). The failure of the Shell group's project to sink the Brent Spar platform off the North Sea illustrates this "life cycle of societal pressures" (Ackerman and Bauer, 1976). The increasingly virulent pressures against Shell (boycott of Shell stations in particular in Germany, occupation of the platform by Greenpeace activists,...) led the company to find a more "Ecological", in particular by recovering materials from the platform. Although this option was not the most economical and that enterprise had all the authorizations to sink the platform reached the end of its useful life, the intensity of societal pressures had considerably reduced the margin of maneuver of the oil group. The societal perspective thus tends to make environmental challenges constraints which, when taken into account, entails costs that are difficult to avoid and proportional to the intensity of the pressures against the enterprise.

The theory of negative externalities and depollution costs is the economic counterpart of this perspective. According to the classic economic approach, the environmental nuisances caused by industrial activity translate into costs that are not borne by the enterprise or integrated into the price of its products: health problems, accelerated corrosion, loss of harvests, deterioration of a recreational or tourist site, depletion of natural resources, etc. These costs are therefore outsourced, i.e. deferred to the community. Environmental pressures and regulatory standards will drive enterprises to internalize these costs through actions to reduce impacts on the natural environment. These depollution actions will therefore translate into charges linked in particular to the acquisition of environmental equipment (air purifiers, filters, cleaner processes, etc.) and operating expenses (labor, maintenance,...).

\subsection{Direct relationship between reduced pollution and increased costs borne by the enterprise}

The direct relationship between the reduction in pollution and the increase in costs borne by the enterprise leads to the calculation of an "optimal level of pollution", defined as the level from which marginal costs to reduce the impact on the environment become greater than the reduction in costs associated with environmental damage (Lipsey, Purvis and Steiner, 1993; Pillet, 1993; Prud'homme, 
1980). This model therefore implicitly considers that depollution actions invariably entail additional costs for the enterprise. On the other hand, negative externalities (damage to the environment, health risks, deterioration of goods) tend to decrease when expenditure on pollution control increases. There is therefore a level of rejection known as "optimal" to balance the costs borne by the enterprise and the damage suffered by the community. In addition to traditional impact studies, according to some authors, this damage can be assessed based on the price that citizens are ready to pay for environmental protection (Gauthier, 2003). This "cost-benefit" analysis, which is generally criticized by environmentalists, assumes, however, that it is possible to put a price on nature. Yet ecosystems and life in general are priceless in themselves, since they escape economic rationality, based on the exchange value of goods (Cairncross, 1992, Passet, 1979).

Other, more empirical, economic analyzes have attempted to model the relationships between environmental investment and the economic situation of enterprises using global statistical data. Thus, numerous studies have shown, in accordance with the classic model of depollution costs, that the development of environmental regulations and the investments made to respond to them tend to have a negative impact on the productivity of enterprises (Denison, 1978; Christainsen and Haveman , 1981; Guollop and Roberts, 1983; Dufour, Lanoie and Patry, 1992). According to Walley and Whitehead (1994), the predominance of the "win-win" rhetoric in recent studies on environmental management is largely unrealistic and risks leading to costly choices that can seriously jeopardize the competitiveness of enterprises. The acquisition of environmental equipment generally involves very heavy investments and whose profitability is low. For example, in the 1990s, the additional annual costs associated with environmental standards imposed by the United States Clean Air Act were estimated at $\$ 4$ billion to $\$ 5$ billion to control sulfur dioxide emissions in American power plants and through investments more than $\$ 37$ billion for petroleum refineries (Cairncross, 1992; Walley and Whitehead, 1994).

This "win-lose" economic hypothesis has environmental and political implications that go far beyond the boundaries of the organization and its strategy. Thus, the refusal by the American administration to sign the Kyoto agreements is justified, according to President Georges Bush, by the harmful impact of such a measure on the economy of the United States. Similarly, Canada's decision to adopt the Kyoto agreements announced at the Johannesburg summit in September 2002 has sparked outcry in certain provinces, most notably Alberta and Newfoundland, which denounce, like the government, the prohibitive economic costs arising from such a commitment.

\subsection{PORTER hypothesis or the environment at the service of productivity}

Based on a conflicting relationship between the economy and the environment, the classical model has been widely contested, since the end of the 1980s, by different approaches, which have endeavored to demonstrate the benefits of integrating ecological concerns into the environment enterprise activity. These approaches have been widely popularized by the principle of "sustainable development", which is central to the work of the World Commission on Environment and Development (1988), which has inspired many studies on the economic benefits of environmental investments. Thus, contrary to the Malthusian proposals of the Club of Rome, the sustainable development strategy maintains that the resumption of growth, associated with a more equitable redistribution of wealth and respect for natural balances is essential to ensure a sustainable 
development mode, it that is to say, a development "which meets the needs of the present without compromising the ability of future generations to meet their own" (World Commission on Environment and Development, 1988, p.51). The Brundtland Commission's optimism about the possibilities of harmonizing the economy and the ecology will facilitate efforts to take into account the sustainable development strategy at international, national, regional and even organizational levels. The proliferation of "green plans", which aim to integrate countries' environmental and economic policies, is part of this philosophy. Thus, many countries such as Canada, Denmark, France, Great Britain, Ireland, Italy, Norway or the Netherlands have implemented, from the early 1990s, plans more or less ambitious to promote a sustainable development strategy based on "win-win" logic (Theys, 1992).

Likewise, from the beginning of the 1990s, numerous studies have focused on promoting the implementation of environmental strategies centered on the principles of sustainable development (Schmidheiny et al., 1992; Landry, 1990; Sala, 1992; Robins, 1992). This work has made it possible to demonstrate various benefits that can result from environmental initiatives: savings in materials and energy, reduction in contaminant treatment costs and waste burial costs, improvement of the enterprise's image, improvement of processes, technological innovations.

Whatever the examples and approaches chosen by these studies, environmental actions appear most of the time as a means of improving the productivity and competitiveness of the enterprise. This "win-win" perspective is often called the "Porter hypothesis", the latter having been one of the first to question the traditional postulate of the negative link between environmental actions and enterprises competitiveness (Porter, 1991; Porter and Van Der Linde, 1995). The questioning of this assumption doesn't directly relate to the binding nature of environmental pressures. According to Porter, the development of environmental regulations, on the contrary, calls for expenditure and transformations which could increase costs. However, meeting these constraints also leads to innovation efforts to improve processes, use inputs more efficiently and find new outlets for the byproducts of production. Supporting examples, Porter believes that the benefits resulting from these measures most often exceed their costs. In fact, the strengthening of regulatory constraints in certain countries, far from curbing the competitiveness of enterprises compared to competitors who are not subject to the same standards, stimulates and tends to improve the competitive position of the least polluting firms on the international markets.

\subsection{Analysis of the relationship between environmental actions and productivity}

Certain success stories from enterprises recognized for their environmental commitment have helped to accredit Porter's thesis. For example, Interface, a company specializing in the manufacture of carpets and textiles, has implemented an ambitious environmental policy focused on the quest for eco-efficiency. This policy has led to major changes in most of the enterprise's activities: product design, processes, quality programs, employee training and marketing policy. The development of Interface's environmental initiatives is not only an objective to be achieved; these initiatives are central to the enterprise's vision, which is to "enable each person to continuously learn and develop" and "to become the first name in the field of industrial ecology". Since 1994, efforts to implement this vision have saved nearly $\$ 80$ million and increased revenues by $20 \%$ while significantly reducing 
waste and consumption of raw materials (Johansen, 1998). The environmental management acronyms used in several multinationals are also indicative of the savings that seem to be able or want to be made by improving eco-efficiency: Prevention Pollution Pays (PPP) at 3M, Waste Reduction Always Pays (WRAP) at Dow Chemicals, "Save Money and Reduce Toxics" (SMART), at Chevron.

Thus, numerous studies have made the discovery of the synergies between reducing pollution and improving productivity an "economist" justification for environmental actions and the renewal of the traditional paradigm on environmental economics (Lanoie and Laplante, 1992; Shrivastava, 1995, Berry and Rondinelli, 1998). Green enterprise commitment should therefore be encouraged by governments and managers, not only for its intrinsic legitimacy but also for its virtuous ripple effect on competitiveness and manufacturing efficiency.

However, more systematic studies conducted since the early 1990s to test Porter's hypothesis have yielded much more nuanced and often contradictory results. This research has often been based on correlation analyzes between the strengthening of regulatory standards in certain sectors and changes in the productivity level of enterprises. While some studies tend to validate Porter's hypothesis (Azzone and Bertèle, 1994; Shrivastava, 1995; Lanoie and Tanguay, 1999), others confirm the main postulates of the classical model (Boyd and McCelland, 1999; Palmer), (Oates \& Portney, 1995).

The analysis of the relationship between environmental actions and productivity therefore remains very controversial. These controversies are linked, to a large extent, to the complexity of environmental measures and to the reducing nature of the "cost-benefit" analysis.

\section{Arbitration and contingency of the COST-BENEFIT analysis}

The previous examples show that the economic consequences of environmental actions do not follow a simple linear relationship. If certain environmental investments have positive economic benefits in the more or less long term and are necessary to ensure the social legitimacy of the enterprise, the actions of depollution can also require heavy expenses and compromise the financial balance of the enterprise. As Palmer, Oates and Portney (1995) show, while it is easy to find success stories like Porter and Van Der Linde, it is also possible to list many cases where the costs associated with environmental pressures have put in financial difficulty of enterprises. The opposition between the two logics mentioned above and which dominates the debates on the economic challenges of environmental actions therefore seems arbitrary, even simplifying.

First, the overall economic benefits of environmental actions depend on the type of industry and the nature of the contaminants considered. It is clear that, for enterprises specializing in the treatment of industrial water for example, the development of environmental concerns constitutes an economic opportunity. In polluting industries, however, environmental investments often appear to be costs, although many environmental actions, such as measures to reduce waste and improve energy efficiency, for example, can translate into substantial savings. Enterprises' environmental programs and their economic impacts therefore do not constitute a homogeneous, monolithic and universal reality. Some initiatives lead to savings in materials or energy, while others involve often 
considerable net costs. For example, Dow Chemical's source reduction program, which reported a $55 \%$ return on investment, relied on a multitude of decentralized initiatives involving strong worker participation (Avila and Whitehead,1994). However, the roughly $\$ 200$ million that the enterprise invested in the environment in the same year resulted in a $16 \%$ negative return on investment. In some cases, environmental investments represent net costs but which can lead, in the long term, to unexpected economic benefits. For example, the American chemical leader has spent hundreds of millions of dollars on pollution control equipment, compensation for damage caused by toxic products, or clean-up operations following accidental spills. However, by forcing the development of one of the most important environmental services in the world (Simon, 1990).

Secondly, in industries subject to strong environmental pressures, investments to reduce pollution appear today much more as necessary, even indispensable, actions than as discretionary investments whose evaluation must be based exclusively on criteria of economic cost-benefit. Enterprises will therefore focus on making the necessary investments to comply with regulatory standards and respond to societal pressures, by favoring the most economical solutions, in particular in a context of recession and budgetary restrictions. This approach will often lead to favoring efficiency criteria over efficiency criteria in achieving environmental objectives. It is in this perspective that the English environmental program BATNEC ("Best Available Techniques Not Entailing Excessive Cost"), for example, is based, which is based on cooperation between inspectors and enterprise managers to implement solutions technological solutions to maximize the relationship between environmental efficiency and the cost of the measures envisaged. The interface between the economy and the environment does not obey here a "win-win" or "win-lose" dichotomous logic but rather in search of a realistic compromise between two dimensions which must not be subordinate to each other.

\section{Results and discussions}

The economic implications of green investments can vary considerably depending on the sector of activity, the objectives, the industrial and regulatory context and the type of action considered. The complexity of ecological problems as well as the plurality and diversity of actions that can be implemented to reduce the impact of industrial activities on the natural environment simplify the classic opposition between the traditional economist perspective and the Porter hypothesis. Like any investment, environmental actions involve a risk that will be all the greater as the expenses are high and the uncertainty will make the forecasts of decision-makers more difficult. The implementation of a preventive approach centered on a logic of "continuous improvement" allows, to a certain extent, to reduce these environmental costs or even bring substantial savings. However, the progress in terms of environmental performance and productivity that can be achieved by this approach remains uncertain and limited. Achieving more ambitious environmental goals often calls for the adoption of palliative technologies that lead to more drastic improvements, but which require costly investments with no effect on productivity.

This contingent and circumstantial nature of the economic implications of environmental actions calls for a broadening and contextualization of reflections on this theme. On the one hand, the "winwin" and "win-lose" logics are based on simplifying assumptions that ignore the complexity and the contingent nature of the interface between economy and environment. On the other hand, these analyzes too often tend to subordinate environmental issues to economic actions, which will favor or 
on the contrary restrict ecological actions according to the anticipated costs or benefits. The question is not so much whether environmental investments are economically beneficial or not, but to understand and promote the conditions which make it possible to improve the efficiency of environmental actions, such as regulations, social pressures or even business strategy make it necessary. As the international standard ISO 9001 (version 2000) indicates, efficiency refers to the "relationship between the result obtained and the resources used". Improving environmental efficiency therefore requires achieving environmental objectives or improving results in this area at the lowest cost or even possibly with economic benefits.

In industrial enterprises, this quest for environmental efficiency depends in particular on the following factors (Figure 1):

- Manufacturing excellence: environmental performance is not only the result of specific programs in this area, but also of efforts to improve productivity: total quality, operations management, innovations, technological management. These efforts are often confused with pollution prevention approaches to the extent that they make it possible to optimize resources by minimizing inputs as well as waste (Roy, Boiral and Lagacé, 2001);

- Technological choices: the installation of depollution systems downstream of the processes (palliative logic) most often results in costs which have a negative impact on productivity. On the other hand, reducing pollution at source (preventive approach) generally leads to savings in materials and energy which improve the efficiency of production activities (Klassen and Whybark, 1999; King and Lenox, 2002). These two approaches are not, however, mutually exclusive. On the enterprise, they are called to coexist, in particular when the environmental objectives are ambitious and require a combination of measures;

- Current and targeted environmental performance: the phenomenon of decreasing marginal efficiency of depollution actions tends to progressively limit the opportunities for improving productivity, in particular if substantial efforts have already been made (Viardot, 1993). As a result, the opportunities for economic gain will, in principle, be easier for enterprises that start implementing environmental programs than for those that are already advanced in the field. Whatever the nature of these programs, the entry into force of much more stringent environmental regulations or more drastic environmental objectives will ultimately require more expensive and less profitable depollution systems;

- Anticipating standards and the equipment renewal cycle: anticipating these pressures is particularly important when the equipment renewal cycle and the resulting innovation process are slow. In this case, it is more difficult or longer to integrate the evolution of environmental constraints in the design of new processes. As Cairncross (1990) points out, the obsolescence of equipment is generally slower in the most polluting industries (textiles, metallurgy, agrifood). In these industries, the tightening of regulatory constraints tends to entail significant costs in order to bring old processes into conformity, the design of which is poorly adapted to new requirements In younger, high-growth enterprise sectors where innovation technology is faster (electronic, computer), frequent changes in production methods make it possible, on the contrary, to adapt processes more flexibly and efficiently to new environmental standards (Russo and Fouts, 1997) 
- Employee mobilization: environmental awareness and staff involvement in pollution reduction programs can lead to significant improvements regardless of major and costly technical changes (Boiral, 2002). On the one hand, changes in certain work habits can reduce certain sources of rejection. On the other hand, process operators often have simple and effective ideas for economically improving environmental performance.

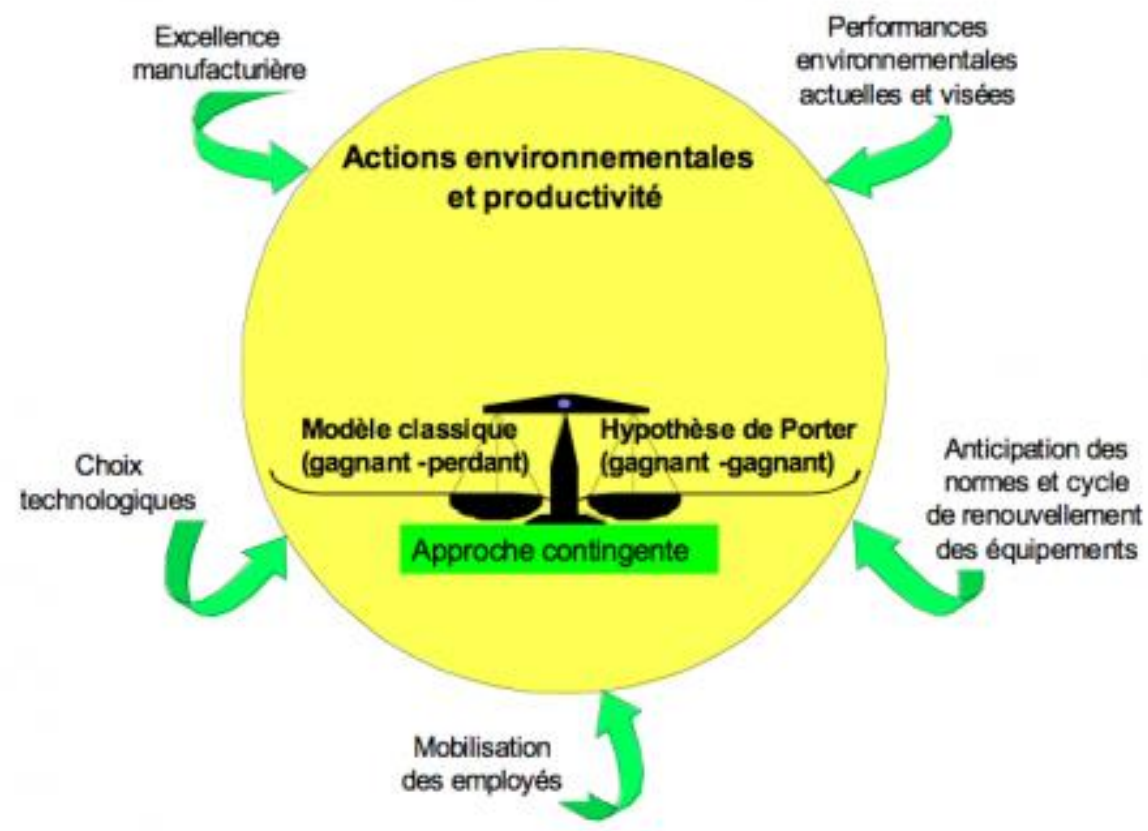

Figure 1: Contingency of the relationships between environment and productivity

\section{Conclusion}

The role of managers and strategic choices in promoting the emergence of a virtuous logic between environment and productivity is not absent, however, On the one hand, regardless of economic considerations, the green sensitivity of managers is not without impact on environmental investment decisions (Bansal and Roth, 2000; Egri and Herman, 2000). On the other hand, as a study of environmental policies carried out with more than 600 American enterprises shows (King and Lenox, 2002), managers tend to underestimate the benefits of preventive approaches on productivity. Finally, pollution prevention actions and the promotion of a logic of continuous improvement require a much broader mobilization of employees than in the case of technical measures, which generally depend on environmental services (Ruiz-Quintanilla, Bunge, Freeman -Gallant and Cohen-Rosenthal, 1996; Boiral, 2002). However, the leadership of managers is necessary or even essential for raising employee awareness and their environmental involvement. The commitment of senior management is the first measure of the ISO 14001 environmental management system.

The effects of environmental actions on productivity therefore depend on external factors and internal practices which makes the polarization of debates in this area arbitrary if not simplistic. Questioning this polarization, which seems more ideological than rational, avoids two types of 
pitfalls. The first is to consider that environmental investments a priori represent prohibitive costs which must, de facto, be avoided or minimized at the risk of threatening economic productivity. This type of argument, often put forward by enterprises and governments (as in the case of the refusal to sign the Kyoto agreements by some countries) appears as an easy justification for the status. The second pitfall is to take the "win-win" doctrine for granted by investing massively in palliative technologies or, on the contrary, to only implement environmental actions deemed "profitable" by ignoring necessary but costly measures.

Whatever options are chosen, environmental actions should not be entirely subordinated to economic considerations deemed more or less favorable but based first and foremost on the concern to respect the integrity of ecosystems and the health of populations. Respect for these fundamental values in any priceless society, it imposes expenses which should not be judged solely on economic criteria.

\section{Acknowledgment}

The author would like to thank the deanship of scientific research and research center for engineering and applied sciences, Majmaah University, Saudi Arabia, for their support and encouragement; also the author would like express our deep thanks to our university, Majmaah University, Saudi Arabia.

\section{References}

[1] Bae, T.J., Qian, S., Miao, C. \& Fiet, J.O. (2014). The relationship between entrepreneurship education and entrepreneurial intentions: A meta-analytic review. Entrepreneurship: Theory and Practice, 38(2), 217254.

[2] Bansal, P. et K. Roth.(2000), « Why Companies Goes Green: A Model of Ecological Responsiveness ». Academy of Management Journal, vol. 43, no. 4, p. 717-736.

[3] Boiral, O.(2002) « Tacit Knowledge and Environmental Management », Long Range Planning, vol. 35, no. 3, p. 291-317.

[4] Boiral, O. et G. Croteau,(2001). "Du développement durable à l'écologie industrielle, ou les métamorphoses d'un concept caméléon ", Xe Conférence de l'Association internationale de management stratégique, Québec, 11-13 juin 2001, Faculté des sciences de l'administration, Université Laval.

[5] Boiral, O. et J. Kabongo,(2004). "Le management des savoirs au service de l'écologie industrielle ", Revue Française de Gestion, vol. 30, no. 149, p. 173-191.

[6] Boiral, O(2003). "Stratégies de dépollution et compétitivité: pour une approche contingente de I'hypothèse de Porter ", Xlle Conférence de l'Association internationale de management stratégique, 6 juin 2003, Les Côtes de Carthage, Tunisie (publication des actes de colloque sur cédérom).

[7] Carsrud, A. \& Brännback, M. (2011). Entrepreneurial motivations: What do we still need to know? Journal of Small Business Management, 49(1), 9-26.

[8] Carsrud, A. \& Brännback, M. (2011). Entrepreneurial motivations: What do we still need to know? Journal of Small Business Management, 49(1), 9-26.

[9] Chen, Y. (2010). Does entrepreneurship education matter to students' entrepreneurial intention? China, s.n. Journal of Small Business Management

[10] Cohen, P., West, S. G., \& Aiken, L. S. (2014). Applied multiple regression/correlation analysis for the behavioral sciences. Psychology Press.

[11] Costello, A. B., \& Osborne, J. W. (2018) “STUDENTS'PERCEPTION OF AUTO-SCORED Revista de la Facultad de Educación 21.2 2018, 21(2), 79-103. 
[12] Costello, A. B., \& Osborne, J. W. (2005). Best practices in exploratory factor analysis: Four recommendations for getting the most from your analysis. Practical assessment, research \& evaluation, 10(7), 1-9.

[13] DPaço, A., Ferreira, J.M., Raposo, M., Rodrigues, R.G. \& Dinis, A. (2015). Entrepreneurial intentions: Is education enough? International Entrepreneurship and Management Journal, 11(1), 57-75.

[14] Egri, C.R. et S. Herman (2005) «Leadership in the North American Environmental Sector: Values, Leadership Styles, and Contexts of Environmental Leaders and their Organizations ", Academy of Management Journal, vol. 43, no. 4, p. 571-604.

[15] Fayolle, A. \& Liñán, F. (2014). The future of research on entrepreneurial intentions. Journal of Business Research, 67(5), 663-666.

[16] Fayolle, A. \& Liñán, F. (2014). The future of research on entrepreneurial intentions. Journal of Business Research, 67(5), 663-666.

[17] Fayolle, A., Gailly, B. \& Lassas-Clerc, N. (2006). Assessing the impact of entrepreneurship education programmes: A new methodology. Journal of European industrial training, 30(9), 701-720.

[18] Gauthier, C.(2003), "What Level of Ecostrategy? ", XIle Conférence de l'Association internationale de management stratégique, 4-6 juin 2003, Les Côtes de Carthage, Tunisie

[19] GÜROL, Yonca et ATSAN, Nuray(2006)"Entrepreneurial characteristics amongst university students: Some insights for entrepreneurship education and training in Turkey. Education Training, 2006, vol. 48, no 1, p. 25-38.

[20] Hessels, J., Millán, J. M., \& Román, C. (2015). The importance of being in control of business: Work satisfaction of employers, own-account workers and employees.

[21] Hockerts.K (2017). Determinants of Social Entrepreneurial. Entrepreneurship Theory and Practice, 105130.

[22] JOHNSON, Richard A. et WICHERN, Dean W. Multivariate analysis. Encyclopedia of Statistical Sciences, 2004, vol. 8.

[23] Jusoh, R., Ziyae, B., Asimiran, S. \& Kadir, S.A. (2011). Entrepreneur training needs analysis: Implications on the entrepreneurial skills needed for successful entrepreneurs. The International Business \& Economics Research Journal, 10(1), 143.

[24] Jusoh, R., Ziyae, B., Asimiran, S. \& Kadir, S.A. (2011). Entrepreneur training needs analysis: Implications on the entrepreneurial skills needed for successful entrepreneurs. The International Business \& Economics Research Journal, 10(1), 143.

[25] Kautonen, T., Gelderen, M.V. \& Fink, M. (2015). Robustness of the theory of planned behaviour in predicting. Entrepreneurship Theory and Practice, 39(3), 655-674.

[26] Kautonen, T., Gelderen, M.V. \& Fink, M. (2015). Robustness of the theory of planned behaviour in predicting. Entrepreneurship Theory and Practice, 39(3), 655-674.

[27] King, A.A. et M.J. Lenox « Exploring the Locus of Profitable Pollution Reduction ». Management Science, 2002, vol. 48, no. 2, p. 289-299.

[28] Miralles, F., Giones, F. \& Riverola, C. (2016). Evaluating the impact of prior experience in entrepreneurial intention. International Entrepreneurship and Management Journal, 791-813.

[29] Mustar, P., Renault, M., Colombo, M. G., Piva, E., Fontes, M., Lockett, A, \& Moray, N. (2006). Conceptualising the heterogeneity of research-based spin-offs: A multi-dimensional taxonomy. Research policy, 35(2), 289-308.

[30] Neck, H.M. \& Greene, P.G. (2011). Entrepreneurship education: Known worlds and new frontiers. Journal of Small Business Management, 49(1), 55-70.

[31] Paço, A., Ferreira, J.M., Raposo, M., Rodrigues, R.G. \& Dinis, A. (2015). Entrepreneurial intentions: Is education enough? International Entrepreneurship and Management Journal, 11(1), 57-75.

[32] Rauch, A. \& Hulsink, W. (2015). Putting entrepreneurship education where the intention to act lies: An investigation into the impact of entrepreneurship education on entrepreneurial behavior. Academy of Management Learning and Education, 14(2), 187-204. 